\title{
Muscle Atonia Is Triggered by Cholinergic Stimulation of the Basal Forebrain: Implication for the Pathophysiology of Canine Narcolepsy
}

\author{
Seiji Nishino, ${ }^{1}$ Mehdi Tafti, ${ }^{1}$ Malcolm S. Reid, ${ }^{1}$ Jeff Shelton, ${ }^{1}$ Jerome M. Siegel, ${ }^{2}$ William C. Dement, ${ }^{1}$ and \\ Emmanuel Mignot ${ }^{1}$ \\ 'Stanford University, Stanford Sleep Disorders Research Center, Palo Alto, California 94304 and 2University of \\ California, Los Angeles, Department of Psychiatry, Neurobiology Research 151A3, Sepulveda, California 91343
}

Narcolepsy is a sleep disorder characterized by excessive daytime sleepiness and rapid eye movement (REM) sleeprelated symptoms, such as cataplexy. The exact pathophysiology underlying the disease is unknown but may involve central cholinergic systems. It is known that the brainstem cholinergic system is activated during REM sleep. Furthermore, REM sleep and REM sleep atonia similar to cataplexy can be triggered In normal and narcoleptic dogs by stimulating cholinergic receptors within the pontine brainstem. The pontine cholinergic system is, therefore, likely to play a role in triggering cataplexy and other REM-related abnormalities seen in narcolepsy. The other cholinergic system that could be involved in the pathophysiology of narcolepsy is located in the basal forebrain (BF). This system sends projections to the entire cerebral cortex. Since acetylcholine release in the cortex is increased both during REM and wake, the basocortical cholinergic system is believed to be involved in cortical desynchrony. In the current study, we analyzed the effect of cholinergic compounds injected into the forebrain structures of narcoleptic and control dogs. We found that carbachol (a cholinergic agonist) injected into the BF triggers cataplexy in narcoleptic dogs while it increases wakefulness in control dogs. Much higher doses of carbachol bilaterally injected in the BF were, however, shown to trigger muscle atonia even in control dogs. These results suggest that a cholinoceptive site in the BF is critically implicated in triggering muscle atonia and cataplexy. Together with similar results previously obtained in the pontine brainstem, it appears that a widespread hypersensitivity to cholinergic stimulation may be central to the pathophysiology of canine narcolepsy. Furthermore, hypersensitivity in the $B F$, an area anatomically connected with the limbic system, would explain why emotional excitation, which is usually an alerting stimulus in normals, triggers cataplexy in narcoleptic dogs.

[Key words: narcolepsy, cataplexy, REM sleep, cholinergic system, $A C h$, basal forebrain]

\footnotetext{
Received Aug. 10, 1994; revised Feb. 13, 1995; accepted Feb. 14, 1995.

We thank P. Hyde, J. Geary, M. Gelb, E. Lister, and the entire staff of Stanford Sleep Research Center and Department of Comparative Medicine. This research was supported by NS 27710 and NS 23724.

Correspondence should be addressed to Dr. Seiji Nishino, Stanford Sleep Disorders Research Center, 701 Welch Road, Suite 2226, Palo Alto, CA 91301. Copyright (C) 1995 Society for Neuroscience 0270-6474/95/154806-09\$05.00/0
}

Human narcolepsy is a sleep disorder characterized by excessive daytime sleepiness, rapid eye movement (REM) sleep at sleep onset, and dissociated REM sleep processes such as cataplexy (attacks of flaccid muscle paralysis triggered by emotional excitation) (Daniels, 1934; Guilleminault et al., 1974; Guilleminault, 1976). Canine narcolepsy is a naturally occurring animal model that presents behavioral, pharmacological, and electrophysiological similarities to the human disorder (Mitler et al., 1974; Baker and Dement, 1985; Mignot et al., 1992; Nishino et al., 1993, 1994). No consistent histopathological finding has been reported in canine and idiopathic human narcolepsy (Mitler et al., 1974; Baker et al., 1982; Erlich and Itabashi, 1986; Aldrich et al., 1994). This suggests that the pathophysiology of narcolepsy involves minute abnormalities of the neurochemical mechanisms regulating sleep rather than a localized lesion or an obvious developmental abnormality in the CNS.

There is compelling evidence that the brainstem cholinergic system is central to the control of REM sleep. The brainstem cholinergic neurons originating in the mesopontine tegmentum (MPT) [lateral dorsal tegmentum (LDT) and pedunculopontine tegmentum (PPT)] send ascending projections to various forebrain structures, such as the thalamus and hypothalamus (Satoh and Fibiger, 1986; Woolf and Butcher, 1986; Hallanger and Wainer, 1988; Semba and Fibiger, 1989), as well as a descending projection to the pontine and medullary reticular formation (Mitani ct al., 1988; Ryc ct al., 1988; Shiromani ct al., 1988). Injection of cholinomimetic agents into the medial-PRF (mPRF) in cats induces REM sleep-like or cataplexy-like states, depending on the site and volume of the injection (George et al., 1964; Mitler and Dement, 1974; Baghdoyan et al., 1984; ValazquezMozezuma et al., 1989). The putative cholinergic REM sleepon neurons have been identified in the MPT (Sakai, 1988; El Mansari et al., 1989; Steriade et al., 1990; Kayama et al., 1992). Furthermore, acetylcholine ( $\mathrm{ACh}$ ) release in the dorsal tegmental field in cats is known to increase during REM sleep (Kodama et al., 1990).

Cataplexy and REM sleep are likely to be regulated by similar brainstem cholinergic mechanisms. Using the canine model of narcolepsy, we have recently demonstrated that local perfusion of a cholinergic agonist, carbachol, into the mPRF induces status cataplecticus (Reid et al., 1994b), and that ACh release in the mPRF increases during cataplexy (Reid et al., 1994c). Narcoleptic dogs are more sensitive to cholinergic stimulation than normal dogs, as lower doses of carbachol are necessary to induce muscle atonia in these animals (Reid et al., 1994b). This 
result, consistent with the previous report that muscarinic receptors in the pontine brainstem are upregulated in narcoleptic dogs (Boehme et al., 1984; Kilduff et al., 1986), suggests that cholinergic hypersensitivity in the mPRF is a critical element in the pathophysiology of canine narcolepsy.

Another cholinergic system that could be involved in the pathophysiology of narcolepsy is the basal forebrain (BF) cholinergic system (nucleus basalis, substantia innominata, diagonal band, and medial septum). This system not only sends projections to the limbic and thalamic systems, but also to the entire cerebral cortex (Divac, 1975; Woolf et al., 1986; Semba and Fibiger, 1989; Semba et al., 1989). This contrasts with MPT projections to the cortex, which innervate only the medial prefrontal lobe (Vincent et al., 1983; Satoh and Fibiger, 1986). The $\mathrm{BF}$ cholinergic system may, therefore, be more dircetly involved in controlling cortical desynchrony during wake and REM sleep (see, Cesamenti et al., 1986; Buzsáki et al., 1988; Sakai et al., 1990; Baghdoyan et al., 1993; Stewart et al., 1984). ACh release in the cortex increases during REM sleep as well as during wake (Kanai and Szerb, 1965; Jasper and Tesier, 1971). These results suggest that the BF cholinergic system could complement MPT cholinergic projections to the thalamus and their well-established function of gating thalamocortical activity (Steriade et al., 1990).

We hypothesized that not only the pontine but also the BF cholinergic systems are involved in narcolepsy. This would explain why narcoleptic subjects show dissociated REM sleep manifestations (REM sleep atonia-like state during wakefulness). In order to explore this possibility, we injected cholinergic compounds into several forebrain structures in both narcoleptic and control dogs and assessed their effects on cataplexy, sleep, and wakefulness.

\section{Materials and Methods}

Animals. Six genetically narcoleptic (four males and two females) and three control (three males) Dobermans from the Stanford University Narcoleptic Canine Colony were included in this study. All dogs were housed in individual stainless steel cages $\left(100 \times 180 \mathrm{~cm}^{2}\right)$, and all experiments were carried out in accordance with the National Institutes of Health Guide for Care and Use of Laboratory Animals. Dogs were fed daily at 9:00 A.M. and exposed to a $12 \mathrm{hr}$ light: dark cycle (lights on at 7:00 A.M. and off at 7:00 P.M.). The mean ages of the six narcoleptic dogs and three control dogs were $3.1 \pm 0.9$ years and $2.6 \pm$ 4.8 years (mean \pm SEM), respectively.

Implantation of guide cannulae and electrodes for polygraphic recordings. All surgical procedure were done aseptically. Following preoperative treatment with atropine $(0.04 \mathrm{mg} / \mathrm{kg}$, i.v. $)$, the animal was anesthetized with pentobarbital $(30 \mathrm{mg} / \mathrm{kg}$, i.v.). Isofluorane inhalant (2\% air mixture) was then used to maintain anesthesia. Electrodes for electroencephalogram (EEG), electromyogram (EMG) and electroocculogram (EOG), and guide cannulae for local injections were implanted with the assistance of a Kopf stereotaxic frame and a reference atlas (Lim et al., 1960). Electrodes for EEG recording were secured to the skull over the midfrontal and lateral parietal cortex, and those for EOG recording were secured into the orbit of the frontal bone. Stranded stainless steel wires were inserted into the dorsal neck muscle for EMG recording. The electrodes were soldered to a 14-pin electrical plug. Twenty gauge thin-wall stainless steel tubes ( $20 \mathrm{~mm}$ long) were used as guide cannulae, and the tips of the cannulae were placed on the surface of the cortical dura. The cannulae were then cemented to the skull and maintained with a stylet. The implantation coordinates were, for $\mathrm{BF}, \mathrm{AP} 29.0-31.0$, L 3.0-5.0, H 8.0 (AP = anterior-posterior, $\mathrm{L}=$ lateral, $\mathbf{H}=$ height from the stereotaxic zero); caudal BF-1, AP 27.0, L 5.0, II 8.0; caudal BF-2, AP 25.0, L 4.0, H 8.0; and anygdala, AP 21.0, L 13.0, $\mathrm{H}$ 9.0. A detailed description of the surgical technique has previously been published (Reid et al., 1994a,b).

Microinjections, cataplexy testings, and sleep recordings. The animals were allowed to recover for 3 weeks after surgery before beginning drug injection trials. For each trial, the head of the animal was restrained throughout the injection procedure (for 6-8 min). The stylet was removed, and a 27 -gauge needle attached by polyethylene tubing to a 5 $\mu 1$ Hamilton syringe was inserted into the guide cannula. The length of the injection needle was previously calculated for each target. The injection needle was slowly lowered to the target below the cortical dura. One microliter or $0.25 \mu l$ of saline or saline containing the active drug was injected into the structure over $2 \mathrm{~min}$ between 10:00 and 11:00 A.M. The needle was kept in place for $3 \mathrm{~min}$ after drug injection and then removed from the guide cannula. The flow in the injection system was tested to confirm that the solution had been delivered.

For each dog, one or two cannulae were placed in each hemisphere to target the BF. Sites were then explored to determine the placement that most effectively modified cataplexy. The cannula targeting the most active site was then used for all experiments reported (cataplexy testings, polygraph recordings, and histological verifications) in this study. Caudal BF (BF-1 and BF-2) or amygdala sites were explored using cannulae implanted in the same hemisphere as the selected BF site.

The time course effect of the compounds on cataplexy of narcoleptic dogs was examined by a behavioral bioassay, the Food Elicited Cataplexy Test (FECT) (Baker and Dement, 1985; Mignol el al., 1988, 1992; Nishino et al., 1989, 1991, 1994). Food, which is a powerful emotional stimulus to these animals, precipitates multiple cataplectic attacks. In the $\mathrm{FEC} I ; 12$ pieces of wet food $\left(1 \mathrm{~cm}^{3}\right)$ are placed $30 \mathrm{~cm}$ apart in a circle on the floor. The dogs have been trained to eat each piece in succession. Typically, a narcoleptic dog will be interrupted by several cataplectic attacks, although the animal will eventually be able to consume all the food. The experimenter records the time spent in these attacks. When the dogs showed status cataplecticus and were unable to complete the FECT in less than $10 \mathrm{~min}, 600 \mathrm{sec}$ was scored as the time spent in cataplexy.

The effect of local injection on slcep and wakefulncss was also cxamined using EEG, EOG, and EMG recordings. All animals were given at least $5 \mathrm{~d}$ of habituation to the experimental room $(3 \times 3 \mathrm{~m})$ before testing. Polygraphic recordings were performed for $4 \mathrm{hr}$ after drug injection in the experimental room with lights on. The animal was left alone in the room but was continuously observed from the adjacent room through a one-way mirror. Recordings were scored in $30 \mathrm{sec}$ epochs for wake, drowsy, light sleep, deep sleep, REM sleep, and cataplexy (for narcoleptic dogs), according to the criteria described by Kaitin et al. (Kaitin et al., 1986) with the following minor modifications. Cataplexy was scored only when the previous two epochs $(1 \mathrm{~min})$ were categorized as wake, drowsy, or cataplexy.

After carbachol injection, narcoleptic dogs exhibit long episodes of muscle atonia with desynchronized EEG that are impossible to identify as either REM sleep or cataplexy. During baseline recordings (after saline injection in the BF) of five narcoleptic dogs, the number of rapid eye movements (REMs) observed during cataplexy was significantly smaller than those observed during REM sleep $10.57 \pm 0.09$ vs 2.13 \pm 0.12 , mean $\pm \mathrm{SEM} / 30 \mathrm{sec}, t(347)=9.6, p<0.01$, Student's $t$ test], and $80.7 \%$ of overall cataplexy epochs had less than two REMs and $66.6 \%$ of overall REM sleep epochs had more than two REMs. The periods of muscle atonia with desynchronized EEG after carbachol injection were therefore divided into two categories, muscle atonia without REMs $(<2 \mathrm{REMs} / 30 \mathrm{sec})$ and muscle atonia with REMs $(\geq 2$ REMs/30 sec)

Drugs. The compounds used for this study were obtaincd from the following sources: carbamylcholine chloride (carbachol), Sigma (St. Louis, MO); atropine and physostigmine, Calbiochem (San Diego, CA); McN-A-343, Research Biochemicals Inc. (Natric, MA). All drug solutions were freshly prepared on each experimental day.

Histological verification of the sites of injection. All the animals were eventually sacrificed to verify injection sites and to map both adjacent cholinergic cell groups, and the projections of the injection site (data will be reported elsewhere). Cholera toxin B subunit (CTb) $(0.1 \mu l$ of $1 \%$ solution in distilled water, List Biological Lab., Campbell, CA) was injected in the BF site $14 \mathrm{~d}$ before the perfusion of the brain. Animals were deeply anesthetized with pentobarbital $(30-40 \mathrm{mg} / \mathrm{kg}$, i.v.), and the brain was perfused through the ascending aorta, first with saline containing $0.1 \%$ heparin, then with ice-cooled fixative in $0.1 \mathrm{M}$ PBS (pII 7.4), containing $4 \%$ paraformaldehyde, $0.1 \%$ glutaraldehyde, and $0.2 \%$ picric acid. Immunohistochemical detection of $\mathrm{CTb}$ was then carried out according to the procedure described by Luppi et al. (1990). The CTb-pretreated sections were then double stained for the mapping of cholinergic neurons using ChAT immunohistochemistry. Briefly, the 


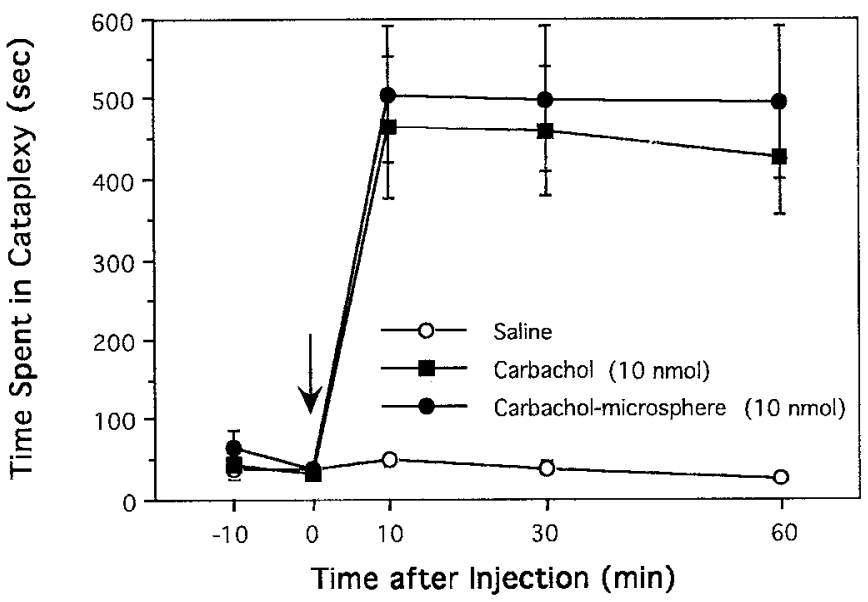

Figure 1. Carbachol (and carbachol conjugated with microspheres) injection in the BF increases cataplexy in narcoleptic dogs. Carbachol, carbachol conjugated with microspheres $(10 \mathrm{nmol} / \mathrm{l} \mu \mathrm{l}$ or $0.25 \mu \mathrm{l})$ or saline $(1 \mu l)$ was injected unilaterally into the $\mathrm{BF}$ of five narcoleptic dogs. Time course effects of the compounds on cataplexy were assessed by the Food Elicited Cataplexy Test (see Materials and Methods). Carbachol and carbachol microspheres injection significantly aggravated cataplexy with a short latency.

slide-mounted sections ( $30 \mu \mathrm{m}$ thick) were incubated for $3-4 \mathrm{~d}$ at $4^{\circ} \mathrm{C}$ in anti-ChAT monoclonal antibody $(1 \mu \mathrm{g} / \mathrm{ml}$, Boehringer-Mannheim, Indianapolis, IN) and then rinsed three times for 15 min in PBS-Tritor and incubated for $90 \mathrm{~min}$ at room temperature in biotinylated anti-rat IgG $(1: 2000$, Vector Lab., Burlingame, CA). This was followed by three 15 min rinses in PBS-Triton and by a 90 min incubation in ABC-HRP complex (1:500-1000, Vector Lab.). After three additional 15 min rinses in PBS-Triton, sections were reacted with $0.02 \% 3,3^{\prime}$-diaminobenzidine-4 HCl (DAB, Sigma, St. Louis, MO) containing 0.003\% hydrogen peroxide. Sections were dehydrated in ethanol, cleaned in xylene, and coverslipped with permount for microscopic examination.

Data analysis. The significance of the time course effects of drugs on cataplexy was assessed using a repeated-measures ANOVA. The significance of drug effects on each sleep parameter was assessed using a paired samples $t$ test. All computation were performed using a personal computer software package (Systat Inc., Evanston, IL).

\section{Results}

Unilateral carbachol $(10 \mathrm{nmol})$ injections into the $\mathrm{BF}$ significantly aggravated the cataplexy of narcoleptic dogs, leading to status cataplecticus in most cases [carbachol vs saline, $F(4,32)$ $=19.1, p<0.01$, a repeated measures ANOVA with a grouping factor (time course $\times$ scssion)] (Fig. 1). Polygraphic recordings confirmed that carbachol induced long-lasting muscle atonia with desynchronized EEG similar to spontaneous cataplexy (Fig. 2). In addition, the effect of carbachol conjugated with latex microspheres $(0.01-0.2 \mu \mathrm{m}$ ) (provided by Dr. Quattrochi, see Quattrochi et al., 1989) was examined, and this preparation (10 nmol of carbachol) was also found to aggravate cataplexy [carbachol-micrushere vs saline, $F(4,32)-20.5, p<0.01$ (time course $X$ session)] with the same latency and potency as the free carbachol injections [carbachol vs carbachol-microshere, $F(4,32)=0.94, D F=4,32, p=0.98$ (time course $\times$ session)] (Fig. 1). Free carbachol (10 nmol) injected into the caudal BF-1 site ( $2 \mathrm{~mm}$ caudal to the BF site, see Materials and Methods) of the narcoleptic dogs significantly aggravated cataplexy $[F(4,16)$ $=3.61, p<0.05$, a repeated measures ANOVA], while car-

Carbachol induced atonia (Narcoleptic dog)

Fronto-parietal EEG

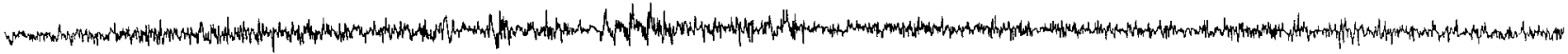

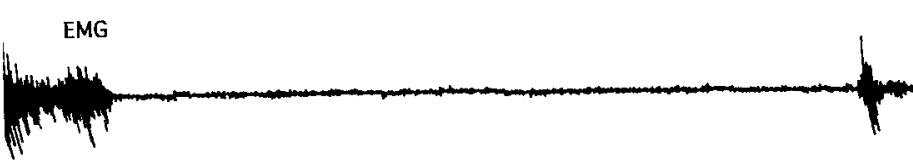

EOG

Spontaneous cataplexy (Narcoleptic dog)

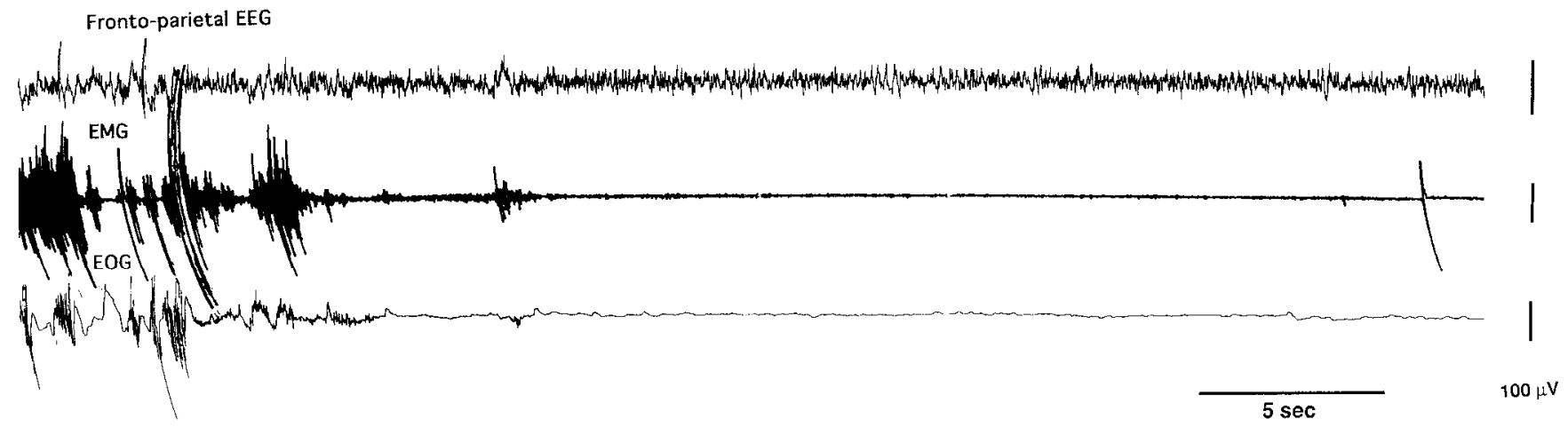

Figure 2. Polygraphic effect of carbachol injected in the BF of narcoleptic dogs. Carbachol injection (10 nmol) in the BF induced a long-lasting muscle atonia with desynchronized EEG in all narcoleptic dogs tested. A typical polygram from a narcoleptic dog after the carbachol injection is shown at the top. As a reference, a polygram of a muscle atonia with desynchronized EEG during spontaneous cataplexy (after saline injection) from the same dog is shown at the bottom. 


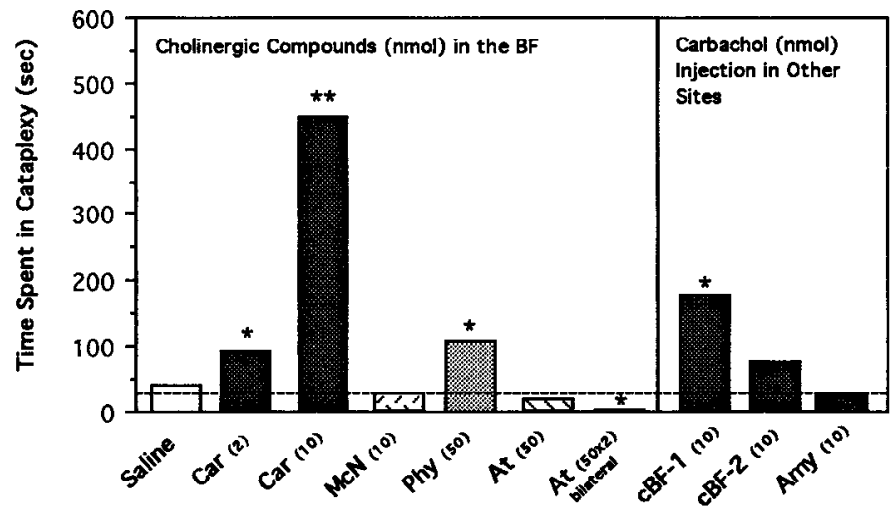

Figure 3. Pharmacological characterization and site specificity of the effect of cholinergic compounds on cataplexy. Carbachol injection into the BF (see Fig. 4 for the injection site) dose dependently aggravated cataplexy. Physostigimine, a choline esterase inhibitor, moderately ag gravated cataplexy, while McN-434, an M1 agonist, had no effect on cataplexy. Bilateral injection of atropine significantly reduced cataplexy. Carbachol was also injected into two other sites in the caudal BF (caudal BF-1 and BF-2, $2 \mathrm{~mm}$ and $4 \mathrm{~mm}$ to the BF site, respectively) and the amygdala (see Materials and Methods). Although a significant aggravation was observed in the caudal BF-1 site, no significant effect was observed after caudal BF-2 or amygdala injection. Four or five (out of six) narcoleptic dogs were used in each drug session. Each bar indicales the Inean of the time spent in cataplexy during three trials (10, 30 , and $60 \mathrm{~min}$ ) after drug injection. A dotted line indicates the mean baseline level of cataplexy $(-10,0 \mathrm{~min}$ before injection) for the overall session $(n=44,32.9 \pm 2.6 \mathrm{sec}$, mean $\pm \mathrm{SEM})$. An asterisk indicates the statistical significance of the change (time course effect) in time spent in cataplexy by the treatment $\left(* * p<0.01,{ }^{*} p<0.05\right.$, a repeated measures ANOVA). Car, carbachol; $M c N, \mathrm{McN}-434 ; P h y$, physostigmine; $A t$, atropine; $c B F$, caudal $B F ; A m y$, amygdala.

bachol injection into the caudal BF-2 (4 mm caudal to the BF site) and the amygdala had no significant effect (Fig. 3).

Pharmacological characterization of the effect of cholinergic compounds on cataplexy demonstrated that bilateral injection of the muscarinic antagonist atropine ( $50 \mathrm{nmol}$ for each site) in the $\mathrm{BF}$ significantly reduced cataplexy, and a selective $\mathrm{M} 1$ agonist, McN-A-343 (10 nmol, unilateral), did not aggravate cataplexy (Fig. 3). Physostigmine (50 nmol), a cholinesterase inhibitor, injected into the BF also significantly aggravated cataplexy $[F(4,16)=3.47, p<0.01)]$ (Fig. 3).

Histological examination demonstrated that the injection sites for the BF in all narcoleptic and control dogs, determined by the $\mathrm{CTb}$ injection, were located within the magnocellular region of the BF [magnocellular preoptic area (POA) and the diagonal band of Broca]. Cholinergic cells stained by ChAT immunohistochemistry were observed in the area surrounding the BF injection sites (Fig. 4).

Polygraphic recordings revealed that the injection of carbachol $(10 \mathrm{nmol})$ in five narcoleptic dogs induced a cataplexy-like state (muscle atonia without REMs, see Materials and Methods) for as much as $30 \%$ of the $4 \mathrm{hr}$ recording period (Fig. 5). In contrast to the effects observed in narcoleptic dogs, the same dose of carbachol $(10 \mathrm{nmol})$ did not induce any cataplexy-like muscle atonia in control dogs $(n=3)$. Carbachol $(10 \mathrm{nmol})$ significantly increased wakefulness $[t(5)=3.2, p<0.05$, paired samples $t$ test], and reduced slow wave sleep (SWS, light sleep and deep sleep) in control dogs $[t(5)=3.2, p<0.05]$. This effect was also observed in narcoleptic dogs $[t(4)=-4.1, p<$ $0.05]$ in addition to the aggravation of cataplexy $[t(4)=4.9, p$ $<0.01]$ (Fig. 5).
The effect of higher doses of carbachol (10, 20, and $50 \mathrm{nmol}$ unilateral and bilateral) was further investigated in three control dogs. Unilateral injections did not induce cataplexy-like behavior in control dogs; however, $50 \mathrm{nmol}$ of carbachol injected bilaterally was found to induce sudden onsets of complete muscle atonia with desynchronized EEG in all three control dogs (see Fig. 6). This cataplexy-like behavior occurred repeatedly for up to $2 \mathrm{hr}$ and was not distinguishable from the status cataplecticus of narcoleptic dogs either by behavioral observations or polygraphic recordings.

\section{Discussion}

In this study, we found that cholinergic stimulation of the $\mathbf{B F}$ with carbachol $(10 \mathrm{nmol})$ induces status cataplecticus in narcoleptic dogs. The histological verification revealed that the injection site in the BF of these dogs was located in the magnocellular POA $(n=4)$ and the diagonal band of Broca $(n=2)$. The most active site is, therefore, likely to be within the magnocellular region of the $\mathrm{BF}$, since carbachol conjugated with latex microspheres (in $0.25 \mu \mathrm{l}$ saline), which do not diffuse more than 200-300 $\mu \mathrm{m}$ from the injection site (Quattrochi et al., 1989), aggravated cataplexy with the same latency and potency as the same dose of free carbachol injections. The results that carbachol injected $2 \mathrm{~mm}$ and $4 \mathrm{~mm}$ caudal to the $\mathrm{BF}$ site was less active and inactive, respectively, further support this interpretation.

Carbachol was also injected into the basololateral amygdala, since it has been reported that this structure receives a heavy cholinergic projection from the $\mathrm{BF}$ and presents a muscarinic receptor-like immunoreactivity (Nagai et al., 1982; Van der Zee et al., 1989). Furthermore, abnormal levels of catecholamines and upregulation of adrenergic alpha- 1 receptors in this structure have been previously reported in narcoleptic dogs (Mefford et al., 1983; Mignot et al., 1988). The negative results of the carbachol effect in the amygdala, however, excludes an involvement of this cholinergic projection for the mediation of the carbachol effect in the BF.

In the magnocellular BF site, atropine, a muscarinic antagonist, significantly reduced cataplexy, while a selective M1 agonist, McN-A-343, did not aggravate cataplexy (Fig. 3). The effect of carbachol on cataplexy in the BF is, thus, probably mediated by an M2 receptor subtype as it is reported for REM sleep and cataplexy in the mPRF (Valazquez-Mozezuma et al., 1989; Reid et al., 1994a). The finding that physostigmine, a cholinesterase inhibitor, also aggravates cataplexy (Fig. 3) suggests that increases in endogenous $\mathrm{ACh}$ levels in the $\mathrm{BF}$ could be involved in physiologically triggered cataplexy in narcoleptic dogs.

The same dose of carbachol $(10 \mathrm{nmol})$ did not induce any cataplexy-like muscle atonia in controls. Polygraphic recordings demonstrated that a $10 \mathrm{nmol}$ carbachol injection in the BF significantly increased wakefulness in these animals. This result is consistent with data previously reported in cats using similar doses of carbachol ( $2.7 \mathrm{nmol}$ bilateral or $22 \mathrm{nmol}$ unilateral) injected into the BF (Sakai et al., 1990; Baghdoyan et al., 1993). Bagdoyan et al. (Baghdoyan et al., 1993) further reported that carbachol injection in the BF of normal cats significantly reduced REM sleep and blocked the ability of REM induction by carbachol injected into the mPRF. Under our recording conditions however, control dogs had only a small amount of REM sleep at the baseline (1.77\% of $4 \mathrm{hr}$ recording time), and no significant decrease $(1.56 \%)$ was observed after the carbachol injection. 

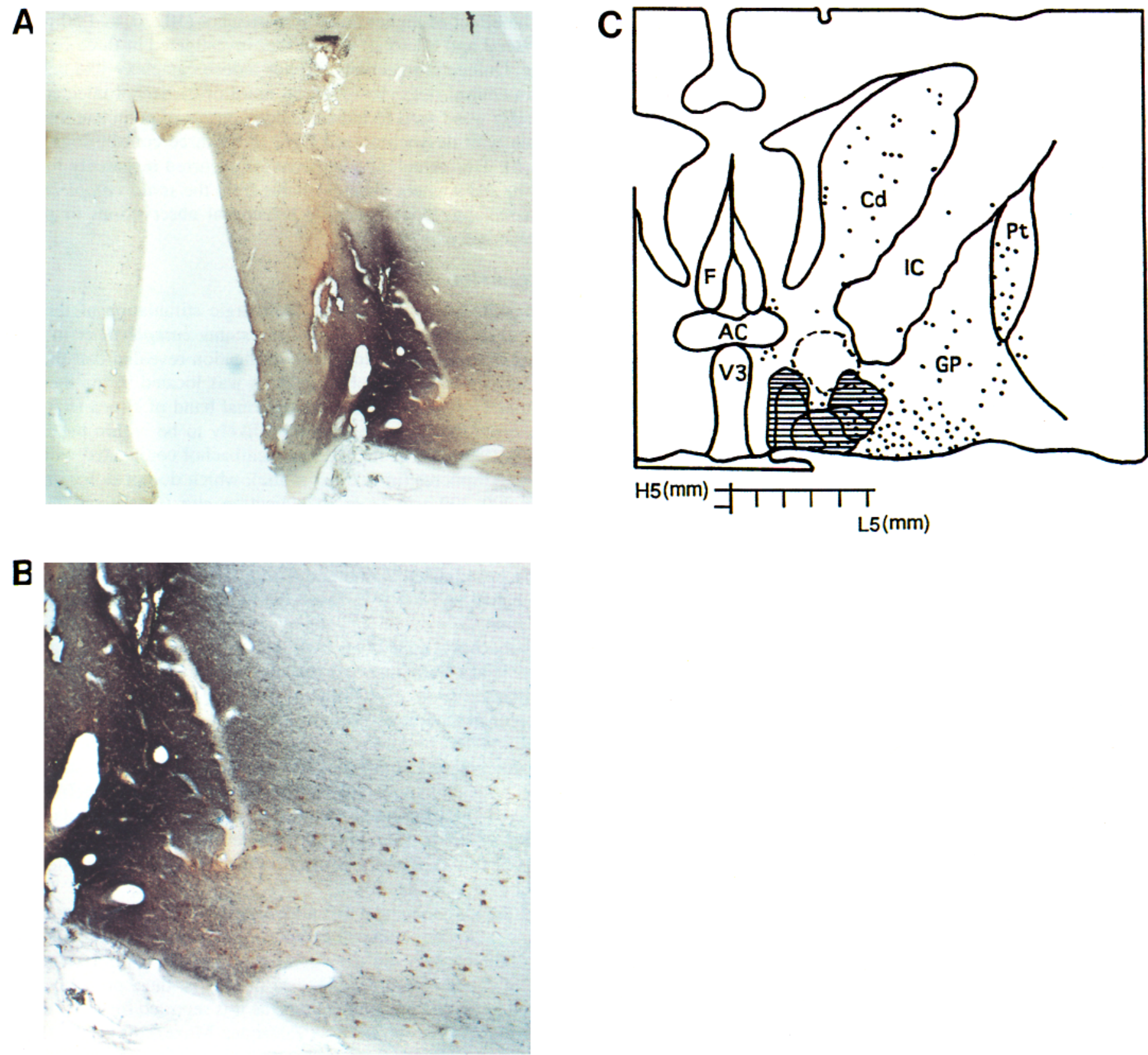

Figure 4. Injection sites of carbachol in the BF $a, b$, The injection site in the BF and adjacent cholinergic cell groups from one of the narcoleptic dogs is shown. The injection site was revealed (diffuse black area) by an immunohistochemical staining of CTb (injection of $0.1 \mu l$ of CTb). Cholinergic neurons, ChAT positive, are observed (small dark brown spots) near the injection site. c, The injection sites for four narcoleptic dogs (hatched areas) and one control dog (encircled with broken line) in the magnocellular POA at the same AP level (AP 25.0, L 2.0-6.0. H 7.0-13.0 by Lim et al., 1960) are illustrated in one figure. The distribution of ChAT-positive neurons (black dots) from one narcoleptic dog is plotted for reference. Injection sites for two other control dogs were also located in the magnocellular POA at different AP levels (AP 24.5, L 3.0-4.0, H 7.0, and AP 24.0, L 4.0, H 7.0). Injection sites for two other narcoleptic dogs were located in the vertical (AP 28.0, L 2.0, H 7.0) and the horizontal (AP 26, L 6.0, H 7.0) limbs of the diagonal band of Broca. Actual injection sites for the BF were found to vary at most $1-5 \mathrm{~mm}$ from the coordinates given in the atlas (Lim et al., 1960), with the observed shift being caudal in most cases. $A C$, anterior commissure; $c d$, caudate nucleus; $F$, fornix; $G P$, globus pallidus; $I C$, internal capsule; $P t$, putamen; $V 3$, third ventricle.

In this study, we further increased the dose of carbachol up to $50 \mathrm{nmol}$ (unilateral and bilateral) in control dogs and found that $50 \mathrm{nmol}$ of carbachol injected bilaterally induced a cataplexy-like state (sudden onset of complete muscle atonia from active-wake state, see Fig. 6) in all three control animals tested. These results parallel the data of an earlier study by HernándezPeón et al. (Hernández-Peón et al., 1963), which reported that
ACh or carbachol injection into the BF induced desynchronized sleep in normal cats. In that study, the dose of carbachol used was not specified, but was likely to be very large since carbachol crystals were inserted through the injection cannulae. Taken together with results obtained by us and others (Sakai et al., 1990; Baghdoyan et al., 1993) using the lower doses of carbachol, it is suggested that very high doses of carbachol are needed to 

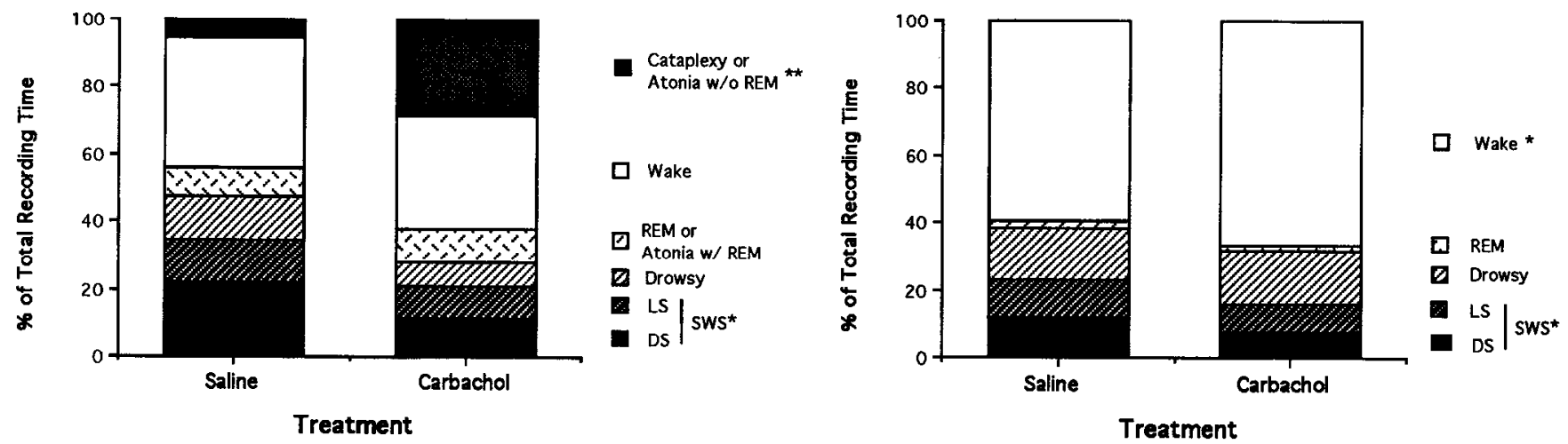

Figure 5. Effect of the BF carbachol injections on specific sleep stages in narcoleptic and control dogs. Carbachol (10 nmol) was injected unilaterally into the BF of five narcoleptic (one session for each animal) and three control (two sessions for each control animal) dogs for polygraphic recordings. Carbachol injections induced long-lasting muscle atonia (without REMs, see Materials and Methods) in narcoleptic dogs for as much as $30 \%$ of the $4 \mathrm{hr}$ recording period. SWS was significantly reduced. In control dogs, the same dose of carbachol (10 nmol) did not induce any cataplexy-like behavior, while it significantly increased the time spent in wakefulness and significantly reduced SWS. Asterisks indicate significant changes $\left({ }^{*} p<0.01,{ }^{*} p<0.05\right.$, paired samples $t$ test) from the saline session.

trigger REM sleep atonia in normal animals when injected in the BF. The fact that cataplexy can be induced by injecting low doses of carbachol in narcoleptic but not control dogs suggests that affected animals are more sensitive to cholinergic stimulation in the BF. We have previously demonstrated that narcoleptic dogs are hypersensitive to cholinergic stimulation in the mPRF. Therefore, these results suggest that a widespread hypersensitivity to cholinergic stimulation might underlie the pathophysiology of canine narcolepsy.

In both the pons and the BF, cholinergic stimulation in the vicinity of cholinergic neurons elicits REM sleep and/or cataplexy. In the pons, the most sensitive area does not overlap with the LDT-PPT areas (see Jones and Beaudet, 1987; Vincent and Reiner, 1987; Mitani et al., 1988; Shiromani et al., 1988). This suggests that the effects of carbachol are mediated via the stimulation of noncholinergic, but cholinoceptive neurons. Lydic et al. (1991) recently demonstrated that unilateral administration of carbachol into the mPRF of cats triggers a REM sleep-like state with an increase of $\mathrm{ACh}$ in the contralateral MPRF, where the main source of cholinergic input is from the MPT (Mitani et al., 1988; Shiromani et al., 1988). This suggests that the stimulation of cholinoceptive MPRF neurons by carbachol secondarily activates MPT cholinergic neurons. In our study of the BF, the carbachol-sensitive area corresponds closely to the magnocellular BF cholinergic neurons (Fig. 4). It was not possible to distinguish cholinergic and cholinoceptive areas because cholinergic neurons are more dispersed and intermingled with noncholinergic neurons in the $\mathrm{BF}$ than in the pons (Martines-Murillo et al., 1990; Fort et al., 1992). Thus, both cholinergic and cholinoceptive neurons could be involved in the cataplexy-inducing effects of carbachol injections in the BF A recent electrophysiological study on guinea pig brain slices demonstrated that an application of muscarine hyperpolarizes cholinergic neurons in the BF (Khateb et al., 1991). In contrast, an in vivo study has shown that putative BF cholinergic neurons antidromically driven from the neocortex are excited by iontophoretic

Carbachol induced atonia (Control dog)

Fronto-parietal EEG

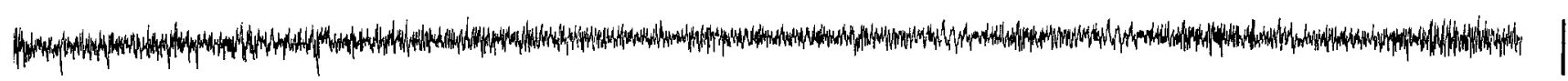

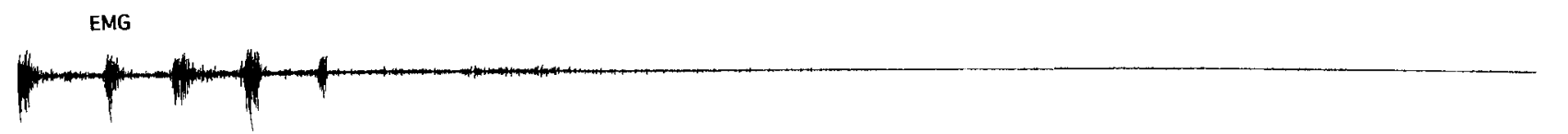

EOG

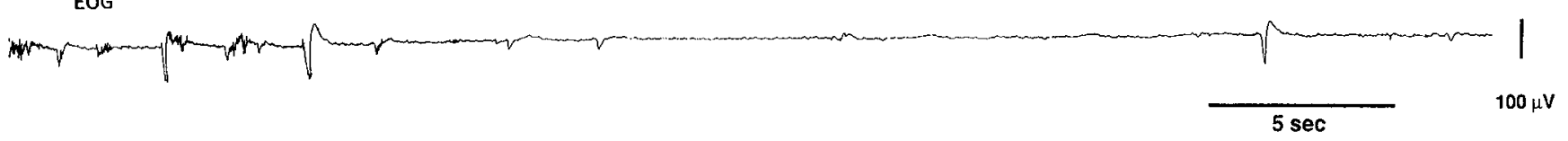

Figure 6. Cataplexy-like behavior can be induced in control animals after injecting high dose of carbachol (50 nmol, bilaterally) into the BF. Unilateral injections (10-50 nmol) did not induce cataplexy in control dogs $(n=3$, one session for each dose), while a very high dose of bilaterally injected carbachol $(50 \mathrm{nmol})$ induced a sudden onset of muscle atonia with desynchronized EEG in all control dogs tested (one session for each of three dogs tested). The effect occurred 10-20 min after injection and lasted up to $2 \mathrm{hr}$. The polygraphic result of a typical experiment obtained in a control dog is shown. 
administration of carbachol or muscarine in the BF (Lamour et al., 1986). This may suggest that the carbachol injection in the BF stimulates noncholinergic cells, which then secondarily stimulates cholinergic neurons, as has been suggested in the mesopontine neurons (see Lydic et al., 1991). This could result in a global activation of a wholc network of cholincrgic cells that might mediate REM sleep-like state changes. The fact that many cholinergic cells in both the BF and MPT have similar electrophysiological properties in vitro (Kamondi et al., 1992; Khateb et al., 1992) further supports the possibility of similar cholinergic-cholinoceptive interactions in both brain areas.

It still remains to be established how pontine and BF cholinergic systems are coordinated during normal and dissociated REM sleep events. In the pons, the region sensitive to cholinergic stimulation is large, and individual behavioral features of REM sleep, such as atonia or ponto-geniculo-occipital waves, can be produced, depending on the stimulation of the specific subregions and the dose of carbachol used (George et al., 1964; Mitler and Dement, 1974; Valazquez-Mozezuma et al., 1989; Baghdoyan et al., 1984; Hobson et al., 1993). Similarly, cholinergic stimulation with small doses of carbachol $(5 \mathrm{nmol}$ unilateral), as far from the pons as the caudal medulla, can also elicit atonia in cats (Lai and Siegel, 1988). In our study, a very high dose of carbachol injected in the BF of control dogs elicited atonia. The $\mathrm{BF}$ region may, therefore, represent the most rostral part of an extended cholinoceptive system, as suggested by Hernández-Peón et al. (1963). We hypothesize further that cholinergic cell groups in the brainstem and the BF are coordinated via their interactions with cholinoceptive neurons. This cholinoceptive system may be involved in ensuring that a global activation of all REM-on cholinergic neurons is maintained in normal conditions once the transition into REM sleep occurs.

That emotional excitation triggers cataplexy is one of the hallmarks of narcolepsy. The BF is anatomically connected with the limbic system, which is believed to be involved in the control of emotions (see Papez, 1937). Furthermore, BF neurons are known to respond to the arousing quality of appetitive stimuli (Rolls et al., 1979; Richardson and Delang, 1991), which is the stimuli we use to induce cataplexy in narcoleptic dogs. For this reason, cholinergic mechanisms within the $\mathrm{BF}$, rather than in the mPRF, are more likely to be the initiators of cataplexy. We hypothesize that emotional excitation increases $\mathrm{ACh}$ release in the BF. Accordingly, in control animals, this would produce alertness in the same way after the injection of low doses of carbachol (Fig. 5). In narcoleptic dogs, however, the same increase in $\mathrm{ACh}$ release during emotions could stimulate a population of hypersensitive cholinoceptive cells. This stimulation would then activate cholinergic cells in the brainstem, resulting in cataplexy or other dissociated REM sleep events. This hypothetical model would also explain why very extreme emotional circumstances, such as intense laughter, have been reported to induce muscle weakness in some normal individuals (Guilleminault et al., 1974). This phenomenon could be explained by an extremely high acetylcholine release in the BF that would he sufficient to overstimulate the system in the absence of any underlying hypersensitivity.

Human studies have demonstrated that symptomatic narcolepsy occurs more frequently in association with lesions of the diencephalon (hypothalamus and third ventricle) than with lesions of the midbrain or pons (Aldrich and Naylor, 1989; Onofrj et al., 1992), suggesting the involvement of forebrain structures in narcolepsy. In this study, we have demonstrated that a cholino- ceptive site in the BF is hypersensitive in canine narcolepsy. This hypersensitivity might be primary or secondary to an abnormality in other neurotransmitter systems. Our series of neuropharmacological and neurochemical studies on canine narcolepsy have suggested that a hypoactivity of monoaminergic systems is implicated in the pathophysiology of canine narcolepsy (see Nishino et al., 1994, for review). It is well known that the activity of adrenergic neurons in the locus coeruleus and serotonergic neurons in the dorsal raphe is abolished during REM sleep (McGinty and Harper, 1976; Aston-Jones and Bloom, 1981). The monoaminergic activity is known to influence the responsiveness of REM sleep/wakefulness state changes to cholinergic stimulation: for example, administered physostigmine enhances arousal during wakefulness (Yamamoto and Domino, 1967), while it induces REM sleep when administered in reserpine-induced monoamine depletion conditions (Karczmar et al., 1969). Therefore, an abnormally reduced monoaminergic tone could also be a causative factor in canine narcolepsy. Cholinergic hypersensitivity, however, is likely to be the critical step leading to the abnormal REM sleep phenomena of narcoleptic dogs.

\section{References}

Aldrich MS, Naylor MW (1989) Narcolepsy associated with lesions of the diencephalon. Neurology 39:1505-1508.

Aldrich MS, Prokopowicz G, Ockert K, Hollingsworth Z, Penny JB, Albin RL (1994) Neurochemical studies of human narcolepsy: alpha-adrenergic receptor autoradiography of human narcoleptic brainstem. Sleep 17:590-597.

Aston-Jones G, Bloom FE (1981) Activity of norepinephrine-containing locus coeruleus neurons in behaving rats anticipates fluctuations in the sleep-waking cycle. J Neurosci 1:876-886.

Baghdoyan HA, Monaco AP, Rodrigo-Angulo ML, Assens F, McCarley RW, Hobson JA (1984) Microinjection of neostigmine into the pontine reticular formation of cats enhances desynchronized sleep signs. J Pharmacol Exp Ther 231:173-180.

Baghdoyan HA, Spotts JL, Snyder SG (1993) Simultaneous pontine and basal forebrain microinjection of carbachol suppresses REM sleep. J Neurosci 13:229-242.

Baker TL, Dement WC (1985) Canine narcolepsy-cataplexy syndrome: evidence for an inherited monoaminergic-cholinergic imbalance. In: Brain mechanisms of sleep (McGinty DJ, Drucker-Colin R, Morrison A, Parmeggiani PL, eds), pp 199-233. New York: Raven.

Baker TL, Forno LS, Foutz AS, Dement WC (1982) Negative neuropathological findings in narcoleptic canine and equine subjects. In: Proceedings of the 22nd annual meeting of the association for the psychophysiological study of sleep, p 157. San Antonio.

Boehme R, Baker TI, Mefford I, Rarchas I, Dement WC, Ciaranello RD (1984) Narcolepsy: cholinergic receptor changes in an animal model. Life Sci 34:1825-1828.

Buzsáki G, Bickford RG, Ponomareff G, Thal LJ (1988) Nucleus basalis and thalamic control of neocortical activity in the freely moving rat. J Neurosci 8:4007-4026.

Cesamenti F, Deffenu F, Abbamondi AL, Pepeu G (1986) Changes in cortical acetylcholine output induced by modulation of the nucleus basalis. Brain Res Bull 16:689-695.

Daniels, LE (1934) Narcolepsy. Medicine 13:1-22.

Divac I (1975) Magnocellular nuclei of the basal forebrain project to neocortex, brain stem, and olfactory bulb. Review of some functional correlates. Brain Res 93:385-398.

El Mansari M, Sakai K, Jouvet M (1989) Unitary characteristics of presumptive cholinergic tegmental neurons during the sleep-waking cycle in freely moving cats. Exp Brain Res 76:519-529.

Erlich SS, Itabashi HH (1986) Narcolepsy: a neuropathologic study. Sleep 9:126-132.

Fort P, Khateb A, Alonso A, Jones BE, Mühlethaler M (1992) Pharmacological heterogeneity of basal forebrain neurones. Soc Neurosci Abstr 18:881.

George R, Haslett WL, Jenden DJ (1964) A cholinergic mechanism in 
the brainstem reticular formation: induction of paradoxical sleep. Int J Neuropharmacol 3:541-552.

Guilleminault C (1976) Cataplexy. In: Narcolepsy (Guilleminault C Dement WC, Passouant, eds), pp 125-143. New York: Spectrum.

Guilleminault C, Wilson RA, Dement WC (1974) A study on cataplexy. Arch Neurol 31:255-261.

Hallanger AE, Wainer BH (1988) Ascending projections from the pedunculopontine tegmental nucleus and the adjacent mesopontine tegmentum in the rat. J Comp Neurol 274:483-515.

Hernández-Peón R, Chavez-Ibarra G, Morgane PJ, Timo-Iaria C (1963) Limbic cholinergic pathways involved in sleep and emotional behavior. Exp Neurol 8:93-111.

Hobson JA, Datta S, Calvo JM, Quattrochi J (1993) Acetylcholine as a brain state modulator: triggering and long-term regulation of REM sleep. Prog Brain Res 98:389-404.

Jasper HH, Tesier J (1971) Acetylcholine liberation from cerebral cortex during paradoxical (REM) sleep. Science 171:601-602.

Jones BE, Beaudet A (1987) Distribution of acetylcholine and catecholamine neurons in the cat brainstem: a choline acetyltransferase and tyrosine hydroxylase immunohistochemical study. J Comp Neurol 261:15-32

Kaitin K, Kilduff T, Dement WC (1986) Evidence for excessive sleepiness in canine narcoleptics. Flectroencephalogr Clin Neurophysio 64:447-454

Kamondi A, Williams JA, Hutcheon B, Reiner PB (1992) Membrane properties of mesopontine cholinergic neurons studied with the whole-cell patch-clamp technique: implication for behavioral state control. J Neurophysiol 66:1359-1371.

Kanai T, Szerb JC (1965) Mesencephalic reticular activating system and cortical acetylcholine output. Nature 205:80-82.

Kayama Y, Ohta M. Jodo E (1992) Firing of 'possibly' cholinergic neurons in the rat laterodorsal tegmental nucleus during sleep and wakefulness. Brain Res 569:210-220.

Khateb $\Lambda$, Serafin M, Jones BE, Alonso $\Lambda$, Mühlethaler M (1991) Pharmacological study of basal forebrain neurons in guinea pig brain slices. Soc Neurosci Abstr 17:881.

Khateb A, Mühlethaler M, Alonso A, Serafin M, Mainville L, Jones BE (1992) Cholinergic nucleus basalis neurons display the capacity for rhythmic bursting activity mediated by low-threshold calcium spikes. Neuroscience 51:489-494

Kilduff T, Bowersox SS, Kaitan KI, Baker TL, Ciaranello RD, Dement WC (1986) Muscarinic cholinergic receptors and the canine model of narcolepsy. Sleep 9:102-107.

Kodama T, Takahashi Y, Honda Y (1990) Enhancement of acetylcholine release during paradoxical sleep in the dorsal tegmental field of the cat brain stem. Neurosci Lett 114:277-282.

Kraczmar AG, Long VG, Scotti de Carolis A (1970) A pharmacological model of paradoxical sleep: the role of cholinergic and monoaminergic systems. Physiol Behav 5:175-182.

Lai YY, Siegel JM (1988) Medullary regions mediating atonia. J Neurosci 8:4790-4796.

Lamour Y, Dutar P, Rascol O, Joberto A (1986) Basal forbrain neurons projecting to the rat frontoparietal cortex: electrophysiological and pharmacological properties. Brain Res 362:122-132.

Lim RKS, Liu C-N, Moffitt RL (1960) A stereotaxic atlas of the dog's brain. Springfield, IL: Books.

Luppi PH, Fort P, Jouvet M (1990) Iontophoric application of unconjugated cholera toxin B subunit (CTb) combined with immunohistochemistry of neurochemical substances: a method for transmitter identification of retrogradely labeled neurons. Brain Res 534:209224.

Lydic R, Baghdoyan HA, Lorinc Z (1991) Microdialysis of cat pons reveals enhanced acetylcholine release during state-dependent respiratory depression. Am J Physiol 261:K766-70.

Martines-Murillo R, Villalba RM, Rodrigo J (1990) Immunocytochemical localization of cholinergic terminals in the region of the nucleus basalis magnocellularis of the rat: a correlated light and electron microscopic study. Neuroscience 36:361-376.

McGinty DJ, Harper RM (1976) Dorsal raphe neurons: depression of firing during sleep in cats. Brain Res 101:569-575.

Mefford I, Baker T, Boehme R, Foutz A, Ciaranello R, Barchas I, Dement WC (1983) Narcolepsy: biogenic amine deficits in an animal model. Science 220:629-631.

Mignot E, Guilleminault C, Bowersox S, Rappaport A, Dement WC
(1988) Effect of $\alpha 1$-adrenoceptors blockade with prazosin in canine narcolepsy. Brain Res 444:184-188.

Mignot E, Guilleminault C, Dement WC, Grumet C (1992) Genetically determined animal models of narcolepsy, a disorder of REM sleep. In: Genetically-defined animal models of neurobehavioral dysfunction (Driscoll P, ed), pp 90-110. Cambridge, MA: Birkäuser.

Mitani M, Ito K, Hallanger AH, Wainer BH, Kataoka K, McCarley RW (1988) Cholinergic projections from the laterodorsal and pedunculopontine tegmental nuclei to the pontine gigantocellular tegmental field in the cat. Brain Res 451:397-402.

Mitler M, Dement WC (1974) Cataplexy-like behavior in cats after microinjection of carbachol in pontine reticular formation. Brain Res 68:335-343.

Mitler M, Boysen M, Campbell L, Dement WC (1974) Narcolepsycataplexy in a female dog. Exp Neurol 45:332-340.

Nagai T, Kimura H, Maeda T, McGeer PL, Peng F, McGeer EG (1982) Cholinergic projections from the basal forebrain of rat to the amygdala. J Neurosci 2:513-520.

Nishino S, Mignot E, Fruhstorfer B, Dement WC, Hayaishi O (1989) Prostaglandin $E_{2}$ and its methyl ester reduce cataplexy in canine narcolepsy. Proc Natl Acad Sci USA 86:2483-2487.

Nishino S, Arrigoni J, Valtier D, Miller JD, Guilleminault C, Dement WC, Mignot E (1991) Dopamine $\mathrm{D}_{2}$ mechanisms in canine narcolepsy. J Neurosci 11:2666-2671.

Nishino S, Arrigoni J, Shelton J, Dement WC, Mignot E (1993) Desmethyl metabolites of serotonergic uptake inhibitors are more potent for supressing canine cataplexy than their parent compounds. Sleep $16: 706-712$

Nishino S, Reid MS, Dement WC, Mignot E (1994) Ncuropharmacology and neurochemistry of canine narcolepsy. Sleep 17:S84-S93.

Onofrj M, Curatola L, Ferracci F, Fulgente T (1992) Narcolepsy associated with primary temporal lobe B-cell lymphoma in a HLA DR2 negative subject. J Neurol Neurosurg Psychiatry 55:853-853.

Papez JW (1937) A proposed mechanism of emotion. Arch Neurol Psychiatry 38:725-743.

Quattrochi J, Mamelak AD, Madison RD, Macklis JD, Hobson JA (1989) Mapping neuronal input to REM sleep induction sites with carbachol-flouresent microsphere. Science 245:984-986.

Reid MS, Tafti M, Nishino S, Siegel JM, Dement WC, Mignot E (1994a) Cholinergic regulation of cataplexy in canine narcolepsy in the pontine reticular formation is mediated by M2 receptors. Sleep $17: 424-435$

Reid MS, Tafti M, Geary J, Nishino S, Siegel JM, Dement WC, Mignot E (1994b) Cholinergic mechanisms in canine narcolepsy: I. Modulation of cataplexy via local drug administration into pontine reticular formation. Neuroscience 59:511-522.

Reid MS, Siegel JM, Dement WC, Mignot E (1994c) Cholinergic mechanisms in canine narcolepsy: II. Acetylcholine release in the pontine reticular formation is enhanced during cataplexy. Neuroscience 59:523-530.

Richardson RT, Delang MR (1991) Electrical studies of the function of the nucleus basalis in primates. In: The basal forebrain: anatomy to function (Napier PW, Kalivas PW, Hanin I, eds), pp 223-252. New York: Plenum.

Rolls ET, Sanghera MK, Roper-Hall A (1979) The latency of activation of neurons in the lateral hypothalamus and substantia innominata during feeding in the monkey. Brain Res 164:121-135.

Rye DB, Lee HJ, Saper CB, Wainer BH (1987) Medullary and spinal efferents of the pedunculopontine tegmental nucleus and adjacent mesopontine tegmentum in the rat. J Comp Neurol 269:315-341.

Sakai K (1988) Exocutive mechanisms of paradoxical sleep. Arch Ital Biol 126:239-257.

Sakai K, El Mansari M, Lin JG, Zhang JG, Vanni-Mercier G (1990) The posterior hypothalamus in the regulation of wakefulness and paradoxical sleep. In: The diencephalon and sleep (Mancia M, Marini G, eds) pp 171-198. New York: Raven.

Satoh K, Fibiger HC (1986) Cholinergic neurons of the laterodorsal tegmental nucleus: efferent and afferent connections. J Comp Neurol $253: 277-302$

Semba K, Fibiger HC (1989) Organization of central cholinergic systems. Prog Brain Res 79:37-63.

Semba K, Reiner PB, McGeer E, Fibiger HC (1989) Brainstem projecting neurons in the rat basal forebrain: neurochemical, topographical, and physiological distinctions from cortically projecting cholinergic neurons. Brain Res Bull 22:501-509. 
Shiromani PJ, Armstrong DM, Gillin JC (1988) Cholinergic neurons from the dorsolateral pons project to the medial pons: a WGA-HRP and choline acetyltransferase immunohistochemical study. Neurosci Lett 95:19-23.

Steriade M, Datta S, Paré D, Oakson G, Curró Dossi R (1990) Neuronal activities in brain-stem cholinergic nuclei related to tonic activation processes in thalamocortical systems. J Neurosci 10:25412559.

Stewart DJ, MacFabe DF, Vanderwolf CH (1984) Cholinergic activation of electrocorticogram: role of the substantia innominata and effects of atropine and quinuclidinyl benzilate. Brain Res 322:219-232.

Valazquez-Mozezuma J, Gillin JC, Siromani PJ (1989) Effect of specific M1 and M2 muscarinic receptor agonists on REM sleep generation. Brain Res 503:128-131.

Van der Zee EA, Matsuyama T, Strosberg AD, Traber J, Luiten PGM (1989) Demonstration of muscarinic acetylcholine receptor-like immunoreactivity in the rat forebrain and upper brainstem. 92:457-485.
Vincent SR, Reiner PB (1987) The immunohistochemical localization of choline acetyltransferase in the cat brain. Brain Res Bull 18:371415.

Vincent SR, Satoh K, Armstrong DM, Fibiger HC (1983) Substance P in the ascending cholinergic reticular system. Nature 306:688-691.

Woolf NJ, Butcher LL (1986) Cholinergic systems in the rat brain: III. projection from the pontomesencephalic tegmentum to the thalamus, tectum, basal ganglia, and basal forebrain. Brain Res Bull 16:603637.

Woolf NJ, Hernit MC., Butcher LL (1986) Cholinergic and noncholinergic projections from the rat basal forebrain revealed by combined choline acetyltransferase and Phaseolus vulgaris leucoagglutinin immunohistochemistry. Neurosci Lett 66:281-286.

Yamamoto K, Domino EF (1967) Cholinergic agonist interactions on neocortical and limbic EEG activation. Int J Neuropharmacol 6:357373. 